\title{
Ion Exchange Membrane for Reverse Electrodialysis
}

\author{
Jaewon Jang* \\ School of Earth Sciences and Environmental Engineering, Gwangju Institute of Science and Technology, Republic of Korea
}

Submission: May 18, 2021; Published: May 26, 2021

*Corresponding author: Jaewon Jang, School of Earth Sciences and Environmental Engineering, Gwangju Institute of Science and Technology, Republic of Korea

\section{Abstract}

Ion exchange membranes (IEMs) are used for exchanging or removing ions from the solutions so that they are fabricated by polymers rather than metals or ceramics. When metal is in contact with the solutions, some reaction or corrosion occurs, and ceramic is difficult to use in membrane form because it is brittle. Also, normal metals and ceramics do not have high ion-exchange properties so that polymers are used widely as a host material of the IEM. The conventional IEMs are either layered membrane consisted of ion exchange material and support layer, and thick bulk membrane. There are no critical problems to use them for water treatment, but they are not suitable for electrochemical application such as reverse electrodialysis (RED). RED is a method of making electricity by sequential ion transport through semi-permeable membranes and electrochemical reaction at the electrode part so that the IEMs need to be developed for getting the structure not to interfere with ion movement through the IEM body. In the RED system, the IEMs are involved in separating ions to create the chemical potential which makes a voltage in the electrochemical system. IEMs for RED has not yet been widely adopted, and most of them are the membrane for electrodialysis (ED). Therefore, we need to study engineering approaches to improve the IEM properties.

Keywords: Ion exchange membrane; Cation exchange membrane; Anion exchange membrane; Polymer; Composite; Structure engineering; Reverse electrodialysis

\section{Introduction}

Ion exchange membrane (IEM) is a semi-permeable membrane that consisted of various polymers. When giving the driving force of ion transport, IEM allows the counter-ions and rejects the coions [1]. The IEM determines the mobility and selectivity of the ions with assumed that the same driving force is given in the system. There are two types of IEM according to the fixed charge in their body, cation exchange membrane (CEM) and anion exchange membrane (AEM). CEM has a negative charge, thereby the anions are rejected and the cations are exchanged by CEM. On the contrary, since AEM has a positive charge, the cations are rejected and the anions are exchanged by AEM (Figure 1). In addition, IEMs are classified into homogeneous and heterogeneous membranes according to their features. Homogeneous membranes can be fabricated by polymerization of monomers or blending and grafting polymers with different moieties [2-4]. Homogeneous membranes have evenly distributed fixed charges throughout the entire body so that uniform properties appear in all regions. Heterogeneous membranes can be obtained by blending charged resin with a binder and casting them on support $[5,6]$.
Usually, the fixed charge distribution of heterogeneous membrane is uneven compared to homogeneous membrane due to the intrinsic drawback of the manufacturing process. In general, therefore, homogeneous membranes have better ion exchange properties than heterogeneous membranes, but heterogeneous membranes are mechanically strong compared to homogeneous membranes. However, both types of membranes can improve their properties through material or structural engineering. There are many high-quality commercial products in the market (Table 1). In the case of CEMs, the most representative commercial product is the Nafion from DuPont. It has a thickness of $178 \mathrm{~nm}$, IEC of $0.84 \mathrm{meq} / \mathrm{g}$, and exact permselectivity is unknown [7]. NEOSEPTA CM-1 of ASTOM, Selemion CMV of Asahi glass, RALEX CM(H)-PES of MEGA, and CEM type 1 of FUJIFILM are also well-developed CEMs. These products showed a thickness of 100-450 nm, IEC levels of $0.84-2.30 \mathrm{meq} / \mathrm{g}$, and permselectivity of $92.0-98.8 \%$ $[5,8]$. In the case of AEM, CJMA-2 of Hefei chemjoy, NEOSEPTA AM-1 of ASTOM, Selemion AMV of Asahi glass, RALEX AM(H)-PES of MEGA, and AEM type 1 of FUJIFILM exhibited thickness of 110- 
$450 \mathrm{~nm}$, IEC values of $0.80-2.20 \mathrm{meq} / \mathrm{g}$, and permselectivity of $90.0-95.0 \%[5,9-13]$.

\section{Features of the conventional ion exchange membranes}

The conventional IEMs have been developed in an aspect of IEC and mechanical endurance because the conventional products are generally used for adsorbing/exchanging ions to the membrane surfaces in a field of water treatment or ED. These are either layered structure that consisted of ion exchange and support layers or the thick bulk membrane that composed with ion-exchange resin and binder polymer (Figure 2). These type of membranes showed excellent performances for exchanging ions in solution or eliminating specific ions from water, but not suitable to maximize the power density of the applications that ions need to move in an opposite area through the IEM, such as RED. The ions would be hindered physically by a support layer or membrane body in conventional cases, no matter how much other properties are excellent. Thus, the idea that finding a novel material, developing a new surface treatment technique, and conducting structural engineering needs to be considered for fabricating novel IEMs for RED. The RED can be an alternative to overcome the dependency of climate and time for producing electricity because it uses saline water as an energy source. Also, there is no pollutant emission during power generation from the RED system. (a)

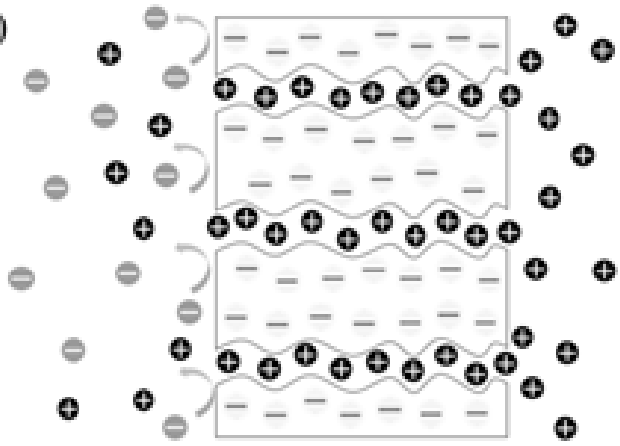

Cation exchange membrane (b)

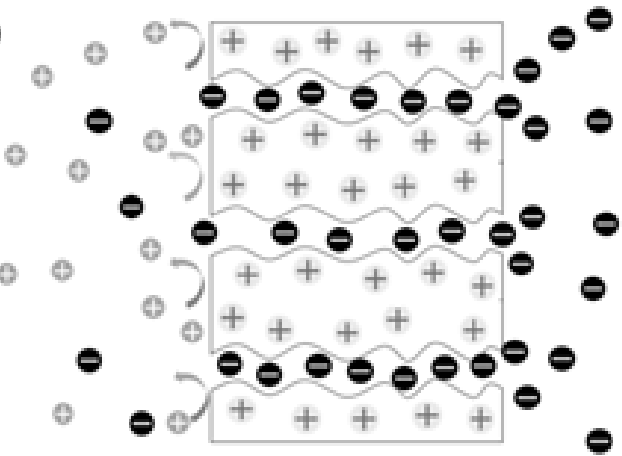

Anion exchange membrane

Figure 1: (a) CEM and (b) AEM, which have fixed negative and positive charge in the matrix, respectively.

(a)

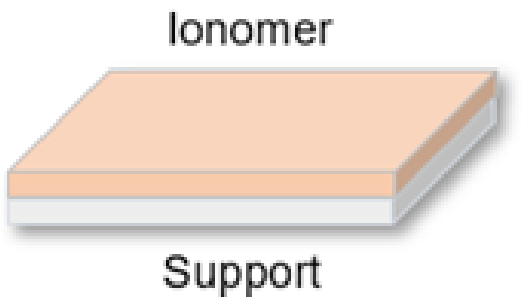

Layered structure (b)

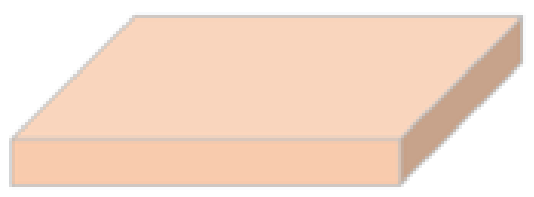

Resin/binder composite

Figure 2: Structure of (a) layered membrane and (b) resin/binder composite membrane. 
Academic Journal of Polymer science

Table 1: Commercial IEMs and their key properties.

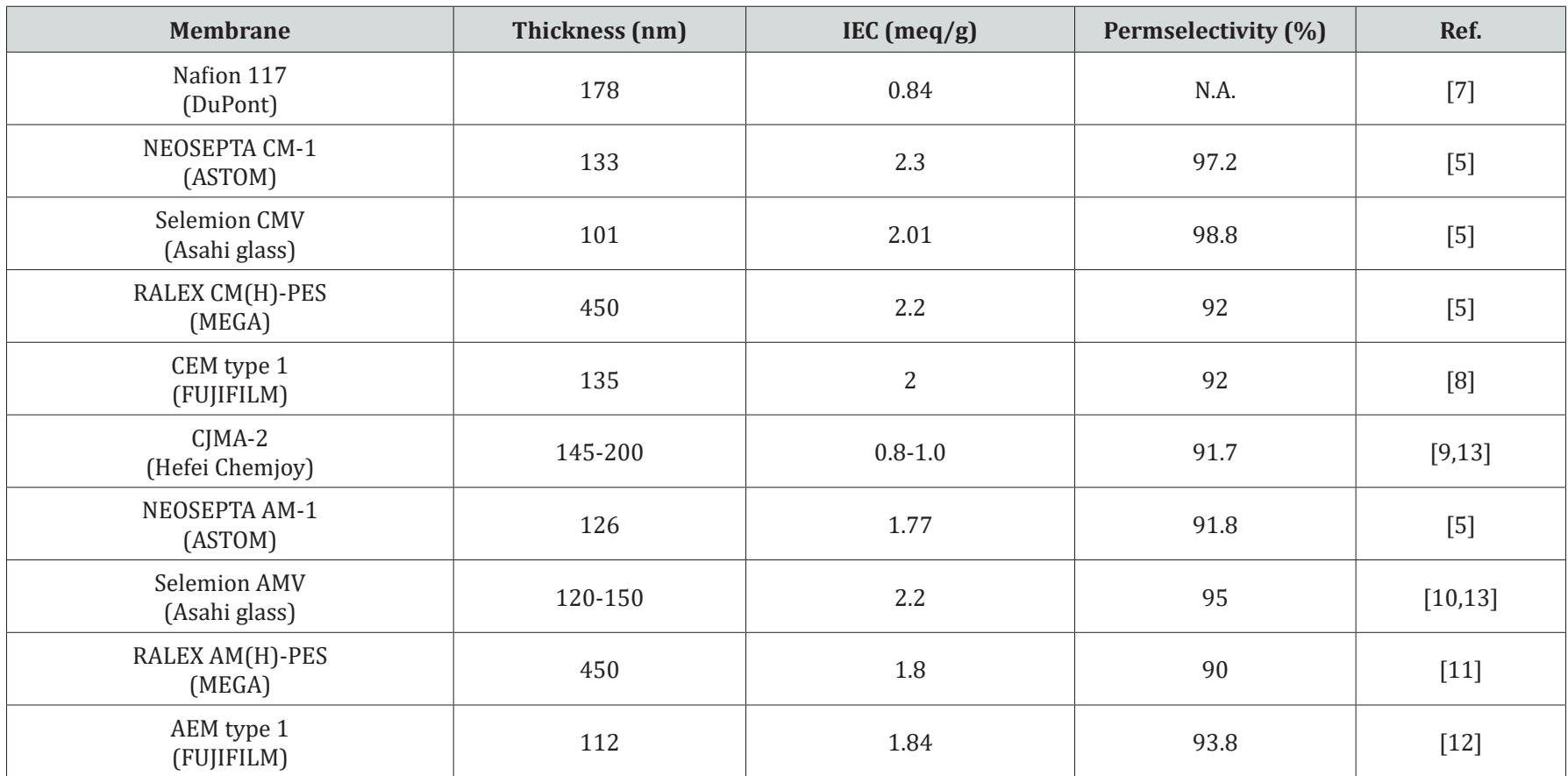

The important parameters of the IEM for RED system are the thickness, membrane structure, IEC, areal resistance, and permselectivity, etc. [14-16]. Among them, the thickness and structure of the IEM influence critically the performance of the RED system because it affects how ions move smoothly by penetrating the IEM body. Another thing to consider is the selectivity between cation and anion. If the ion penetrates the IEM easily, the selectivity of IEM is low because it has a trade-off relation between ion conductivity and selectivity. Therefore, it is very important to develop IEMs which has high ion conductivity and selectivity, simultaneously, for expanding the application area of IEMs to electrochemical energy generation.

\section{Operating mechanism and stack configuration of the RED system}

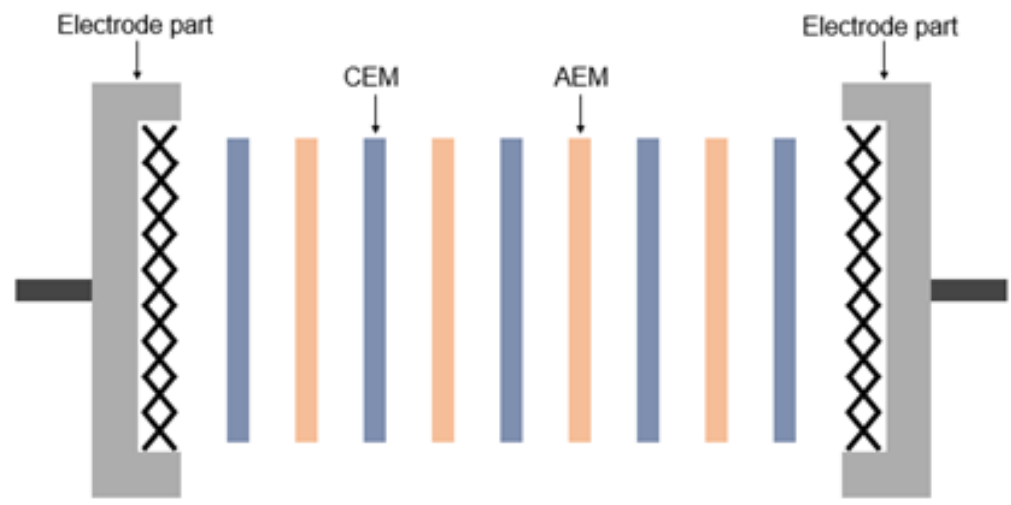

Figure 3: RED stack configurations.

The RED system can convert ionic to electric current by circulating two feed solutions that have different salinity, it is just an inverse procedure of the ED system. Salts or solutes in feed solutions are adsorbed to IEM by the induced potential difference between electrodes in the ED process so that the dilute and the concentrate are obtained [14,17]. However, RED makes the ions transport through the IEMs without an applying potential, and current is generated by a redox reaction at the electrode parts. In other words, the concentration difference between the two feeds is the driving force to move the ions, and the alternating CEM and 
AEM make the ions separate. Thus, high and low salinity solutions need to be supplied alternately across the IEMs for inducing concentration difference. The separation of cation and anion creates a chemical potential in the system so that electrochemical reactions occur to generate electric current (Figure 3) [18-21]. The larger the concentration difference, the higher the power density can be obtained theoretically, but the power density would be decreased owing to an increase of internal resistance in the real case. To enhance the maximum power density, it needs to maintain a high concentration difference between the two feeds with preventing the increase of internal resistance at the same time. IEM is the key to solve this issue. If the IEM performance is improved, the internal resistance of the system would be maintained at a low level even the concentration difference is increased. Therefore, the power density of RED can be determined by the properties of IEM assuming that all conditions of the systems are constant.

\section{Tailor-made ion exchange membranes}

Many commercial IEMs are on the market, but they still need to develop for adopting in electrochemical energy generation by overcoming their drawbacks. The methods related to crosslinking (or grafting) other polymers, and incorporating hetero materials on the membrane have been studied. Pal S, et al. [22] evaluated homogeneous phase crosslinked poly(acrylonitrile-co2-acrylamido-2-methyl-1-propanesulfonic acid) (PAN-co-PAMPS) network CEM with controlling the mol ratio of monomers (AN and AMPS) [22]. By using a PAN-PAMPS-1 membrane including 15 mol\% PAMPS, pretty good mechanical ability (tensile strength of $16.4 \mathrm{Mpa}$ ) and electrochemical performance (FCD of 0.757 $\mathrm{meq} / \mathrm{cm}^{3}$ and transport number of 0.92 ) were obtained due to its uniform phase mixing of ionic domains and hydrophobic domains. $Y$. Chen's group attempted to blend nanoparticles in IEM that were organic-inorganic nanocomposite CEMs such as sulfonated iron (III) oxides $\left(\mathrm{Fe}_{2} \mathrm{O}_{3}-\mathrm{SO}_{4}{ }^{2-}\right)[23,24]$ and sulfonated silica $\left(\mathrm{SiO}_{2}-\mathrm{SO}_{3} \mathrm{H}\right)$ [25] to improve the IEC, resistance, and permselectivity. The $\mathrm{Fe}_{2} \mathrm{O}_{3}-\mathrm{SO}_{4}{ }^{2-} / \mathrm{sPPO}$ nanocomposite CEM was prepared by phase inversion method using the mixture of $\mathrm{Fe}_{2} \mathrm{O}_{3}-\mathrm{SO}_{4}{ }^{2-}$ particles and sPPO solution. This IEM showed AR of $0.82 \Omega \mathrm{cm}^{2}$, permselectivity of $85.6 \%$, and enhanced gross power density of $1.4 \mathrm{~W} / \mathrm{m}^{2}$ [23]. $\mathrm{SiO}_{2}-\mathrm{SO}_{3} \mathrm{H} / \mathrm{sPPO}$ nanocomposite CEM was fabricated by phase inversion using the mixture solution. It exhibited AR of $0.85 \Omega \mathrm{cm}^{2}$ and higher gross power density than that of commercial CEM $(1.3$ $\mathrm{W} / \mathrm{m}^{2}$ ) [25].

Yang S, et al. [26] incorporated ion exchangeable materials into the porous membrane. This is a roll-to-roll (R2R) porefilling process consisting of pretreatment, impregnation, photopolymerization, and polishing. The filler material was synthesized by mixing anionic/cationic electrolyte, crosslinking agent, and a photoinitiator. Thus, both CEM and AEM can be fabricated, respectively, depending on which electrolyte is selected and mixed. The pore-filled CEM (PCEM) showed IEC of 1.839 meq/g, AR of
$0.475 \Omega \mathrm{cm}^{2}$, and permselectivity of $96 \%$. Also, the pore-filled AEM (PAEM) exhibited IEC of $1.645 \mathrm{meq} / \mathrm{g} 1$, AR of $0.661 \Omega \mathrm{cm}^{2}$, and permselectivity of $94.3 \%$ [26,27]. Gao $\mathrm{H}$, et al. [9] engineered the surface of AEMs via layer-by-layer (LBL) method with negatively charged poly(styrenesulfonate) (PSS) and positively charged poly(ethyleneimine) (PEI) polyelectrolytes. This membrane has 7.5 bilayers showed excellent anti-organic fouling characteristics and permselectivity. the antifouling potential also increased $30.29 \%$ higher than the pristine membrane and the ratio of transport number between $\mathrm{Cl}^{-}$and $\mathrm{SO}_{4}{ }^{2-} \mathrm{P}_{\mathrm{SO}_{4}^{2-}} \mathrm{cl}^{-}$was improved from 1.10 (pristine) to 2.44 . These results consequently have been enhanced the power density generation of RED by up to $17 \%$ [9]. Hong JG, et al. [28] fabricated the hybrid IEMs by the chemical reaction using poly (diallyldimethylammonium chloride) (PDDA) for AEMs and the sulfated polyvinyl alcohol (sPVA) as a hydrophilic polymer with sulfonated poly (2,6-dimethyl-1,4phenylene oxide) (sPPO) for CEMs to improve AR, permselectivity, and power density [28-30]. R.A. Tufa et al. fabricated a polymer layer consisted of polypyrrole (PPy) and chitosan (CS) to prohibit the passage of the multivalent ions. The modified IEM showed improvement of open circuit voltage (OCV) and power density of $20 \%$ and $42 \%$, respectively, compared to the pristine IEM [31].

\section{Conclusion}

Since the past, IEMs have been developed with the application of various polymer materials. As a result, high-quality commercial IEMs are being distributed on the market in recent years. These are quite suitable for application in the water treatment field, but their disadvantage is poor ionic conductivity for electrochemical energy applications. Therefore, as the researches introduced briefly in this review, it is necessary to continuously try to apply various materials on IEM, and further studies to suggest a novel structure of the membrane are also needed.

\section{Acknowledgment}

This work was supported by the GIST Research Project grant funded by the GIST in 2021.

\section{References}

1. Tanaka Y (2015) Ion exchange membranes: fundamentals and applications.

2. Nagarale RK, Gohil GS, Shahi VK (2006) Recent developments on ion-exchange membranes and electro-membrane processes, Advances in Colloid and Interface Science 119(2-3): 97-130.

3. Xu T (2005) Ion exchange membranes: State of their development and perspective, Journal of Membrane Science 263(1-2): 1-29.

4. Mei Y, Tang CY (2018) Recent developments and future perspectives of reverse electrodialysis technology: A review, Desalination 425(1): 156-174.

5. Dlugolecki P, Nymeijer K, Metz S, Wessling M (2008) Current status of ion exchange membranes for power generation from salinity gradients. Journal of Membrane Science 319: 214-222.

6. Molau GE (1981) Heterogeneous ion-exchange membranes. Journal of Membrane Science 8(3): 309-330. 
7. Safronova EY, Golubenko DY, Shevlyakova NV, D'yakova MG, Tverskoi VA, et al. (2016) New cation-exchange membranes based on crosslinked sulfonated polystyrene and polyethylene for power generation systems. Journal of Membrane Science 515(1): 196-203.

8. Golubenko DV, Pourcelly G, Yaroslavtsev AB (2018) Permselectivity and ion-conductivity of grafted cation-exchange membranes based on UV-oxidized polymethylpenten and sulfonated polystyrene. Separation and Purification Technology 207(22): 329-335.

9. Gao H, Zhang B, Tong X, Chen Y (2018) Monovalent-anion selective and antifouling polyelectrolytes multilayer anion exchange membrane for reverse electrodialysis. Journal of Membrane Science 567(1): 68-75.

10. Veerman J, Jong RM, Saakes M, Metz SJ, Harmsen GJ (2009) Reverse electrodialysis: Comparison of six commercial membrane pairs on the thermodynamic efficiency and power density. Journal of Membrane Science 343(1-2): 7-15.

11. Product data sheet (RALEX membrane AMHPES).

12. Yang S, Kim WS, Choi J, Choi YW, Jeong N, et al. (2019) Fabrication of photocured anion-exchange membranes using water-soluble siloxane resins as cross-linking agents and their application in reverse electrodialysis. Journal of Membrane Science 573(1): 544-553.

13. Lv Y, Yan H, Yang B, Wu C, Zhang X, et al. (2018) Bipolar membrane electrodialysis for the recycling of ammonium chloride wastewater: Membrane selection and process optimization. Chemical Engineering Research and Design 138: 105-115.

14. Hong JG, Zhang B, Glabman S, Uzal N, Dou X, et al. (2015) Potential ion exchange membranes and system performance in reverse electrodialysis for power generation: A review. Journal of Membrane Science 486(15): 71-88.

15. Choi J (2001) Pore size characterization of cation-exchange membranes by chronopotentiometry using homologous amine ions, Journal of Membrane Science 191(1-2): 225-236

16. Villafaña L, Reyes DM, González OA, Suárez T, Jaime JS (2019) Custom-Made Ion Exchange Membranes at Laboratory Scale for Reverse Electrodialysis, Membranes 9(11): 145.

17. Porter MC (1990) Handbook of industrial membrane technology, Noyes Publications, Park Ridge, USA.

18. Veerman J, Saakes M, Metz SJ, Harmsen GJ (2010) Electrical Power from Sea and River Water by Reverse Electrodialysis: A First Step from the Laboratory to a Real Power Plant. Environ Sci Technol 44(23): 9207-9212.

19. Tedesco M, Scalici C, Vaccari D, Cipollina A, Tamburini A, et al. (2016) Performance of the first reverse electrodialysis pilot plant for power production from saline waters and concentrated brines. Journal of Membrane Science 500(15): 33-45.
20. Oh Y, Jeong Y, Han SJ, Kim CS, Kim H, et al. (2018) Effects of Divalent Cations on Electrical Membrane Resistance in Reverse Electrodialysis for Salinity Power Generation. Ind Eng Chem Res 57(46): 15803-15810.

21. Guler E, Zhang Y, Saakes M, Nijmeijer K (2012) Tailor-Made Anion-Exchange Membranes for Salinity Gradient Power Generation Using Reverse Electrodialysis. ChemSusChem 5(11): 2262-2270.

22. Pal S, Mondal R, Guha S, Chatterjee U, Jewrajka SK (2019) Homogeneous phase crosslinked poly(acrylonitrile-co-2-acrylamido-2-methyl-1-propanesulfonic acid) conetwork cation exchange membranes showing high electrochemical properties and electrodialysis performance. Polymer 180(10): 121680.

23. Gi Hong J, Chen Y (2015) Evaluation of electrochemical properties and reverse electrodialysis performance for porous cation exchange membranes with sulfate-functionalized iron oxide. Journal of Membrane Science 473(1): 210-217.

24. Hong JG, Chen Y (2014) Nanocomposite reverse electrodialysis (RED) ion-exchange membranes for salinity gradient power generation. Journal of Membrane Science 460(15): 139-147.

25. Gi Hong J, Glabman S, Chen Y (2015) Effect of inorganic filler size on electrochemical performance of nanocomposite cation exchange membranes for salinity gradient power generation. Journal of Membrane Science 482(15): 33-41.

26. Yang S, Choi YW, Choi J, Jeong N, Kim H, et al. (2019) R2R Fabrication of Pore-Filling Cation-Exchange Membranes via One-Time Impregnation and Their Application in Reverse Electrodialysis. ACS Sustainable Chem Eng 7(14): 12200-12213.

27. Yang S, Choi YW, Choi J, Jeong N, Kim H, et al. (2019) Green fabrication of pore-filling anion exchange membranes using R2R processing. Journal of Membrane Science 584(15): 181-190.

28. Hong JG, Park TW, Dhadake Y (2019) Property evaluation of custom-made ion exchange membranes for electrochemical performance in reverse electrodialysis application. Journal of Electroanalytical Chemistry 850(1): 113437.

29. Hong JG, Park TW (2018) Electrochemical characterizations and reverse electrodialysis performance of hybrid anion exchange membranes for salinity gradient energy. Journal of Electroanalytical Chemistry $817(15):$ 134-140.

30. Zhang H, Jiang D, Zhang B, Hong JG, Chen Y (2017) A Novel Hybrid Poly (vinyl alcohol) (PVA)/Poly (2,6-dimethyl-1,4-phenylene oxide) (PPO) Membranes for Reverse Electrodialysis Power System. Electrochimica Acta 239(10): 65-73.

31. Tufa RA, Piallat T, Hnát I, Fontananova E, Paidar M, et al. (2020) Salinity gradient power reverse electrodialysis: Cation exchange membrane design based on polypyrrole-chitosan composites for enhanced monovalent selectivity. Chemical Engineering Journal 380(15): 122461. 
This work is licensed under Creative Commons Attribution 4.0 License

DOI: 10.19080/AJOP.2021.05.555654
Your next submission with Juniper Publishers will reach you the below assets

- Quality Editorial service

- Swift Peer Review

- Reprints availability

- E-prints Service

- Manuscript Podcast for convenient understanding

- Global attainment for your research

- Manuscript accessibility in different formats

( Pdf, E-pub, Full Text, Audio)

- Unceasing customer service

Track the below URL for one-step submission https://juniperpublishers.com/online-submission.php 